\title{
Does Fixed-Term Employment Have Spillover Effects on the Well-Being of Partners? A Panel Data Analysis for East and West Germany
}

\author{
Sonja Scheuring ${ }^{1}$ D . Jonas Voßemer ${ }^{2} \cdot$ Anna Baranowska-Rataj $^{3} \cdot$ Giulia Tattarini $^{4}$
}

Accepted: 29 December 2020 / Published online: 19 January 2021

(c) The Author(s) 2021

\begin{abstract}
This paper answers three research questions: What is the impact of fixed-term employment on the well-being of partners? How do these spillover effects differ by gender, and do gender differences depend on socialization in East or West Germany? Do individual wellbeing, perceived job insecurity, and financial worries mediate the spillover effects? We use longitudinal data from the Socio-Economic Panel (SOEP), 1995-2017, and a sample of heterosexual couples living together, to estimate fixed-effects panel regression models. In contrast to previous studies, we consider asymmetric effects of entering and leaving fixedterm contracts by focusing on transitions from unemployment into fixed-term and fixedterm into permanent jobs. Confirming previous research on spillover effects of unemployment, we find that fixed-term re-employment increases partners' well-being and that these effects are larger in case of re-employment by men and partners' socialization in West Germany. We also show that transitions from fixed-term to permanent jobs do not substantially increase the well-being of partners with little differences by gender and place of socialization. While the spillover effect of re-employment is mediated by changes in the well-being of the individual re-entering the labor market, changes in job insecurity and financial worries due to transitions from fixed-term to permanent jobs are too small to produce meaningful effects on well-being. Although fixed-term contracts have been referred to as a new source of inequality, our results show that they cause little difference in the well-being of individuals and their partners and that finding a job matters more than the type of contract.
\end{abstract}

Keywords Fixed-term employment $\cdot$ Well-being $\cdot$ Spillover effects $\cdot$ Panel data $\cdot$ Mediation analysis · Germany

Supplementary information The online version of this article (https://doi.org/10.1007/s10902-02000353-2) contains supplementary material, which is available to authorized users.

Sonja Scheuring

sonja.scheuring@uni-bamberg.de

1 University of Bamberg, Bamberg, Germany

2 MZES Mannheim Centre for European Social Research, Mannheim, Germany

3 Umeå University, Umeå, Sweden

4 WZB Berlin Social Center, Berlin, Germany 


\section{Introduction}

Employment is a key determinant of well-being, and more specifically, life satisfaction (Luhmann et al. 2012), i.e., the balance between individual expectations regarding life and the fulfillment of these expectations (Veenhoven 2009). The flexibilization of labor markets over the last three decades led to growing concerns about job insecurity (Kalleberg 2018), and, in particular, the potential negative effects of fixed-term contracts for well-being (De Witte et al. 2016). In response to employers' demands for flexibility, governments deregulated employment protection and promoted the use of fixed-term jobs. These jobs are characterized by a predetermined expiry date, which leaves it up to employers to decide whether to continue the employment relationship. In Germany, about $40 \%$ of newly created jobs start with a fixed-term contract (Bossler et al. 2019), which underlines the importance of understanding their impact on the well-being of individuals and their partners.

On the one hand, fixed-term contracts are hoped to support the labor market integration of the unemployed (Barbieri 2009) and intended to serve as a stepping stone towards permanent employment. Since unemployment has detrimental and long-lasting consequences for the well-being of individuals (Wanberg 2012; Mousteri et al. 2018), governments have seen fixed-term contracts as a promising tool for improving the labor market prospects of disadvantaged groups (Korpi and Levin 2001; DiPrete et al. 2006) and subsequently their well-being.

On the other hand, it is also assumed that fixed-term contracts are in many ways inferior to permanent contracts. The concern is that they go along with chronic job insecurity and that workers are trapped in the secondary labor market segment, which offers lower job quality (De Cuyper et al. 2009). Therefore, fixed-term employees experience a lack of certainty and planability regarding their future, which worsens their well-being. Some even argue that these jobs have similar or worse consequences than unemployment, because the anticipation of a job loss is more stressful than the actual joblessness itself (Inanc 2018).

Given these two perspectives, a rich literature on the consequences of fixed-term contracts on well-being developed (for an overview see Imhof and Andresen 2018; De Cuyper et al. 2008; Virtanen et al. 2005). Previous research often compares fixed-term with permanent contracts and refers to the entrapment scenario by emphasizing the fears associated with these jobs. In line with this view, a large share of cross-sectional studies reports negative effects (for overview see De Cuyper et al. 2008). Some longitudinal studies also point at a disadvantage among temporary workers (Dawson et al. 2017; De Graaf-Zijl 2012). Other longitudinal studies reveal an ambiguous picture, with some finding substantial positive effects of permanent over fixed-term employment (e.g., Gash et al. 2007), while others report only minor differences (Gebel and Voßemer 2014).

Despite the desired integrational function (stepping stone scenario), few studies compare fixed-term contracts to unemployment. Although most of these studies find that fixedterm jobs are preferable to unemployment (Gundert and Hohendanner 2014; Gash et al. 2007), some theoretically assume and empirically find no differences in well-being (Chambel et al. 2016). Other studies show that insecure employment has even more negative effects than unemployment (Burchell 1994; Kim and von dem Knesebeck 2015).

Scholars have started to consider that job insecurity may affect not only employees with fixed-term contracts, but also their partners. Employment contracts may affect decisions made jointly by the couple. For example, fixed-term employment of one partner can postpone childbirth, decrease the likelihood of marriage, and the chance of home ownership (Baron and Rapp 2019; Auer and Danzer 2016). However, despite 
this research on couples, almost no studies have investigated so-called spillover effects, that is the impact of fixed-term employment of one person on the well-being of their partner. This lack of studies is surprising, as such spillover effects have been previously found for unemployment and job losses (Marcus 2013; Nikolova and Ayhan 2019). The only exception is Inanc (2018), who shows that in the United Kingdom (UK) the negative impact of fixed-term compared to permanent contracts on well-being extends to the partner and is of similar size to the spillover effect of unemployment. The lack of research on spillover effects of fixed-term jobs on family members is an important issue, as its costs or benefits might be seriously misjudged if the focus is on the directly affected individuals only.

The main goal of this paper is to extend research on the spillover effects of fixed-term employment on the well-being of partners. We seek to make three contributions to the literature. First, our main contribution to research on the well-being consequences of fixedterm contracts is the analysis of spillover effects in the German context, thereby extending the only previous study on this topic for the UK (Inanc 2018). Germany is particularly interesting, since its labor market is regulated with a rather strict separation between the primary, advantageous segment with mostly permanent and securely employed individuals and the secondary, disadvantageous segment, including lower quality jobs with e.g., fixed-term contracts (for a detailed discussion of the German labor market see Gundert and Hohendanner 2014). Thus, the effects might be even more detrimental than for the UK, a country with a flexible labor market.

Second, as Inanc (2018) highlights the heterogeneity in spillover effects by gender, an additional contribution is to investigate how women and men react differently to fixedterm employment of their partners. The German context offers a unique opportunity in this respect. While East and West Germany share both labor market and family policies, they still differ in terms of gender norms and roles, which even affect the cohorts born after reunification (Ebner et al. 2020; Bauernschuster and Rainer 2012). We consider how gender differences in the spillover effects depend on partners' place of socialization in either East or West Germany to improve our current understanding of the conditions under which gender differences in spillover effects emerge. The place of socialization provides information about gender role attitudes, which are passed on in the primary socialization from parents to children and should differ between East and West Germany. Whereas previous studies on the effects of fixed-term employment on well-being already found important differences by countries (Täht et al. 2020; Karabchuk and Soboleva 2020), no studies so far have examined the relevance of the place of socialization with respect to spillover effects.

Third, we shed light on the plausibility of the theoretical explanations put forward for spillover effects. We empirically test whether changes in the individual well-being, perceived job insecurity, and financial worries resulting from labor market transitions transmit to the partners' well-being. While these mediators are derived from theoretical models and have been suggested as relevant (Silla et al. 2009), they have not yet been empirically tested in the context of spillover effects.

To answer the research questions, we use longitudinal data from the German SocioEconomic Panel (SOEP), 1995-2017, and apply fixed-effects panel regression models. To bridge the two opposing perspectives, which emphasize the benefits and costs of fixed-term jobs, we compare fixed-term jobs to both unemployment and permanent jobs. We focus on transitions from unemployment to fixed-term and fixed-term to permanent employment. These specific transitions are most closely related to the debates that motivate our study, that is fixed-term contracts as a means of labor market integration for the unemployed and its potential role as a stepping stone. 


\section{Theory and hypotheses}

The benefits of stable employment for individual well-being can be understood from Warr's vitamin model (Warr 2017). This theory explains how environmental factors determine the well-being of individuals. The vitamins refer to twelve distinct factors, which include the opportunity for personal control, social contact, availability of money or career outlook, and other factors. Different domains of life, such as work or family, provide these benefits. In analogy to vitamins, these factors and their components are in over- or under-dosage expected to be harmful for well-being.

When referring to the work context, distinct job situations offer different amounts of vitamins. In line with previous studies (Gebel and Voßemer 2014; Scherer 2009), we assume a continuum from unemployment, which offers the least vitamins, to permanent employment, which offers the most vitamins, with fixed-term contracts somewhere in between the extremes. Compared to permanent employment, fixed-term employment offers poorer working conditions (Booth et al. 2002) and less economic security, which negatively affects the controllability and planability of life (Bosmans et al. 2016; Lazarus and Folkman 1984). Hence, these jobs differently affect the vitamin balance of individuals and consequently their well-being.

But how do these effects then transfer to the partner? The spillover-crossover model can shed light on this question (Bakker and Demerouti 2013; Rodríguez-Muñoz et al. 2014). This model distinguishes intra-individual spillover effects, i.e., bad mood at work transmits to home, from inter-individual crossover effects, i.e., bad mood of an individual transmits to closely related individuals, such as the partner. In line with many other researchers, we use the term 'spillover' to cover both intra- and inter-individual effects (Inanc 2018; Marcus 2013; Nikolova and Ayhan 2019) that lead to a transmission of effects from one partner to the other.

\subsection{The spillover effects of fixed-term employment on subjective well-being}

The work-related sphere of life may affect the way that individuals feel and behave. Previous research documents consequences such as concentration difficulties, elevated irritability, stress, and anxiety, having less energy and vigor, social withdrawal, and less support towards the partner (Danner-Vlaardingerbroek et al. 2013; Jiang and Lavaysse 2018; Mantler et al. 2005; Repetti and Wang 2017). When individual well-being declines, the resulting emotional reactions and behaviors can be a strain on closely related people, such as partners, which can in turn deteriorate their well-being (Rook et al. 1991; Bakker et al. 2009). Apart from being exposed to behavioral changes and a lack of emotional availability and support from the persons, partners may experience a deterioration in well-being due to empathy, i.e., sharing the emotional states and well-being of the persons.

There are also alternative mechanisms that may drive the effects that can occur at the partnership level. Some mechanisms relate to the need of couples to plan their life decisions together, considering the employment situations of both partners (Blom et al. 2020). Perceived job insecurities and financial worries might prevent shared future planning regarding home ownership or childbearing (Blossfeld et al. 2005; Baron and Rapp 2019). Referring back to the vitamin model (Warr 2017), when individuals gain vitamins through re-entering the work environment or by a transition from fixed-term to permanent jobs, these can be utilized to satisfy shared goals of partners. 
Following these arguments, the scale of employment situations related amounts of vitamins, ranging from unemployment, through fixed-term contracts, to permanent employment, is associated not only with individual well-being, but also with the well-being of partners. The transition to more secure positions is linked to a gain in vitamins. Thus, if an individual makes a transition from unemployment to fixed-term employment, the positive feelings about regaining financial resources and other functions of work might go beyond this individual and extend to the partner. Moreover, such 'upward' transitions enable couples to fulfil shared goals, which affect both partners' well-being.

H1a A transition from unemployment into fixed-term employment as compared to remaining unemployed positively affects the well-being of one's partner.

H1b A transition from fixed-term into permanent employment as compared to remaining in fixed-term employment positively affects the well-being of one's partner.

\subsection{Gender differences and how they vary by place of socialization}

According to the doing gender theory (West and Zimmermann 1987), individuals expect that their partners behave in gender-specific ways that shape the division of labor in couples. More specifically, men are supposed to be the breadwinners and women the homemakers. Gainful employment, which enables men to satisfy the material needs of a household, is understood as a signal of masculinity. Unemployment represents a deviation from gender-specific behavior for men, but not for women. Women can substitute employment by engaging in their alternative and socially acceptable role as housewives, which can protect their well-being (Nordenmark and Strandh 1999).

Fixed-term employment exceeds unemployment for the associated vitamins, as it enables men to fulfill their normative obligations by providing material resources to the household. When compared to permanent employment, fixed-term employment can, however, also be seen as a deviation from masculinity. Due to the lower job quality, there is a lower likelihood to be able to provide the family with a stable income (Inanc 2018). Therefore, when the male partner makes an 'upward' transition regarding the employment status, this enables the breadwinner norm to be met and thus satisfies the expectations of the female partner. This expectation does not apply to similar transitions of women and their male partners' well-being, since, according to doing gender theories, it is not the key role of women to earn a living.

H2a The positive spillover effects of a transition from unemployment into fixed-term employment as compared to remaining unemployed on the well-being of the partners will be stronger for female than for male partners' well-being.

H2b The positive spillover effects of a transition from fixed-term employment into permanent employment as compared to remaining in fixed-term employment on the well-being of the partners will be stronger for female than for male partners' well-being.

What doing gender exactly means is determined by contexts such as socialization in East or West Germany. The roles described above are more firmly entrenched and transferred in primary socialization in conservative societies (Sainsbury 1996). Germany has the special situation of two contexts with different gender role attitudes within one country. 
The legacy of the GDR can still be seen today (Ebner et al. 2020). The meaning of doing gender and the importance of gender should therefore depend on the socialization in East or West Germany. In the GDR, a dual-earner model with a strong labor force participation of women shaped individuals' gender norms towards an egalitarian model. Primary socialization in the family and secondary socialization in the school promoted equal gender roles. West Germany, on the other side, with its traditional gender roles, was and is a standard example of the male-breadwinner model (Bauernschuster and Rainer 2012).

For women who have been socialized in West Germany, a suboptimal employment position of the male partner should reflect a stronger deviation from the gender-specific behavior of being the breadwinner than for women socialized in East Germany. By contrast, since gender roles have been more equal in East Germany, it should not be relevant what gender the individual who experiences the 'upward' transition is. The effects should be equally beneficial to the partner. In conclusion, gendered spillover effects should be more relevant for the partners' well-being in case of socialization in West than in East Germany.

H3a The more positive spillover effect of a transition from unemployment into fixed-term employment as compared to remaining unemployed on the well-being of female than male partners will be stronger for affected partners who have been socialized in West than in East Germany.

H3b The more positive spillover effect of a transition from fixed-term into permanent employment as compared to remaining in fixed-term employment on the well-being of female than male partners will be stronger for affected partners who have been socialized in West than in East Germany.

\subsection{Factors mediating the spillover effects}

A few studies have argued that fixed-term employment is equally or even more harmful than unemployment regarding well-being (Burchell 1994; Inanc 2018). Most research, however, assumes the opposite. Fixed-term employment compared to unemployment offers vitamins like financial resources, social contacts as well as social standing (Gash et al. 2007), which should improve the well-being of individuals. By comparison, permanent contracts offer greater job security and as previous studies show a higher income (Booth et al. 2002). As a result, compared to fixed-term employment, permanent employment offers more vitamins, which enhance the job satisfaction, and consequently the well-being of individuals.

These improvements due to 'upward' transitions do not only occur within the working domain, but also transfer to the family life, which boosts the relationship quality (Blom et al. 2020). The corresponding employment transitions reduce the pressure and stress caused by insecurity and reduced planability of the previous employment status. If individuals are less distressed and have a higher well-being, this also transmits to the well-being of their partners (Westman 2016).

H4a The positive spillover effect of a transition from unemployment into fixed-term employment as compared to remaining unemployed on the well-being of the partner will be partly mediated by changes in the well-being of the individual who experiences the transition. 
H4b The positive spillover effect of a transition from fixed-term into permanent employment as compared to remaining in fixed-term employment on the well-being of the partner will be partly mediated by changes in the well-being of the individual who experiences the transitions.

Finally, while an individual under-dosage of all vitamins of the unemployed should explain positive spillover effects for transitions into fixed-term employment, the difference in the vitamins provided by fixed-term compared to permanent jobs is not so clear. In terms of income differentials, fixed-term jobs might be considered by employers as a prolonged probationary period (Booth et al. 2002). Fixed-term employees may therefore receive a lower salary than permanent employees, which leads to more financial worries. Financial worries make it more difficult for couples to achieve common goals. If fixed-term employees make the transition to permanent employment, the financial difficulties should decrease. In addition, as fixed-term jobs expire, workers may perceive job insecurity, which decreases as they make the transition into permanent employment. Therefore, the 'upward' employment transition reduces stress and negative emotions and thus increases well-being (Warr 2017). This well-being boost might accordingly transmit to the partner through empathy.

H5 The positive effect of a transition from fixed-term into permanent employment as compared to remaining in fixed-term employment on the well-being of the individual who experiences the transition will be partly mediated by changes in job insecurity and financial worries.

\section{Methods}

\subsection{Data and Sample}

We use data from the Socio-Economic Panel (SOEP), which began in 1984 (Liebig et al. 2019). The SOEP is an annual household panel survey designed to be nationally representative of the German adult population. Nearly 15,000 households and 30,000 individuals participate (Goebel et al. 2019). For our analyses, the SOEP has three main advantages. First, it offers detailed annual data on activity status, type of contract, and well-being. Second, we have independent information from both partners, as each adult household member is interviewed separately. Third, the SOEP is one of the longest running household panel surveys, which allows us to study the spillover effects of specific employment transitions. More specifically, we can relate changes in the well-being of partners to changes in the activity status and type of contract of individuals.

For the analyses, we select an initial sample of cohabiting and married heterosexual couples living together, where both partners participate in the personal interview. We only use waves from 1995 or later, as information on the type of contract for the previous years is incomplete. To focus on the working age population, we restrict our sample to couples where both partners are between 18 and 65 years old. As we want to investigate the spillover effects of fixed-term employment in comparison to both unemployment and permanent employment, our analyses focus on two specific transitions: (1) from unemployment to fixed-term and (2) from fixed-term to permanent employment. 
These transitions directly relate to the debates that motivate our study. We focus on the role of fixed-term contracts as a means of labor market integration for the unemployed and as a stepping stone from fixed-term to permanent jobs. This study design reduces ambiguities that are associated with the reverse transition from permanent to fixed-term jobs. Within one job, transitions from permanent to fixed-term jobs are prohibited by German labor law. Thus, these transitions will always be associated with a change of jobs, which potentially includes an additional period of non-employment. As a result, it is difficult to assess which changes are responsible for effects on the wellbeing of partners (i.e., contract status or intermediate non-employment).

Our study design regarding the focus on specific employment transitions allows a relaxation of the assumption of symmetric effects. Symmetry in effects is an implicit assumption in standard specifications of fixed-effects models (Allison 2019). We assume asymmetry, because it is theoretically argued that "losses loom larger than gains" (Kahneman and Tversky 1979; Hobfoll 1988). In addition, a recent study on the effects of fixed-term contracts on individuals' well-being shows that transitions from fixed-term to permanent employment and vice versa have effects of different magnitude (Schumann and Kuchinke 2020). Thus, the study points to an asymmetry of effects. While fixedeffects panel analyses in previous studies (Inanc 2018) implicitly assume symmetric effects (Allison 2019), our focus on specific transitions makes no assumptions in this regard.

We further restrict our sample to couples where at least one partner is at risk of experiencing a transition of interest between two yearly interviews $t$ and $t+1$. This includes couples where at least one partner makes the transition from either unemployment to fixed-term or fixed-term to permanent employment (treatment spells). The definition also includes couples where at least one partner continuously remains in the original activity status and contract type (control spells). The latter couples provide information on how the well-being of the partner would have changed in the absence of a transition from either unemployment to fixed-term or fixed-term to permanent employment (Brüderl and Ludwig 2015).

We finally exclude couples with missing values on the variables of interest and restrict the sample to couples observed at least twice. For the analyses of transitions from unemployment to fixed-term employment, this leaves us with 2373 couples and 9531 coupleyears, while for transitions from fixed-term to permanent employment we have data on 2990 couples and 16,418 couple-years. In these samples, we observe 536 and 560 transitions from unemployment to fixed-term employment and 1409 and 1567 transitions from fixed-term to permanent employment by men and women, respectively.

\subsection{Measures}

\subsubsection{Dependent variable}

Our outcome is the life satisfaction of the partner, which primarily captures the cognitive component of subjective well-being (Veenhoven 2009). Partners are asked how satisfied they are with life, all things considered, with answers ranging from 0 "completely dissatisfied" to 10 "completely satisfied" on an 11-point scale. Global life satisfaction scales have been shown to be valid, reliable, and sensitive to change, making them well-suited for our analyses (Diener et al. 2013). 


\subsubsection{Independent variables}

Our independent variable, employment status, combines information on activity status and type of contract to distinguish registered unemployment, fixed-term, and permanent employment. Fixed-term employment encompasses all different forms of employment that have a pre-defined date of contract termination. This definition can include fixed-term contracts with one employer, temporary agency work on a fixed-term contract, as well as casual or seasonal work.

We construct treatment and control spells for our transitions of interest. For transitions from unemployment to fixed-term employment, the treatment spells consist of all years in consecutive unemployment before and all years in consecutive fixed-term employment after the transition between two yearly interviews $t$ and $t+1$. The control spells consist of all years in consecutive unemployment. Spells are censored if individuals are observed in any other than the mentioned employment statuses (e.g., permanent employment), information is missing, or the couple separates. Analogous definitions apply for transitions from fixed-term to permanent jobs, but here the control spells refer to continuous fixed-term employment.

Our analyses exclude any years in self-employment or inactivity of the individual experiencing the transition, but partners can take any employment status. We cannot rule out that individuals switch jobs between interviews or that they have an intermediate short period of unemployment. It might be that our control group includes some persons in more insecure employment situations. Therefore, the effects of a transition from a fixed-term to a permanent contract might be overestimated.

\subsubsection{Moderators}

To examine whether spillover effects differ by gender as well as whether gender differences vary by place of socialization, we measure individuals' gender $(1=$ female, $0=$ male $)$, as identified by the interviewer and partners' place of socialization (1=East Germany, $0=$ West Germany). The latter is indicated by the place of residence of the partner in 1989 shortly before the reunification of Germany. The variable is intended to capture the effects of primary and secondary socialization in the GDR. These stages of socialization are assumed to have lasting effects on individuals' gender roles even until today (Carter 2014). As movements between East and West Germany were quite rare before the fall of the wall, this information is the best available measure for the place where people were socialized. For the few partners born after 1989, we use information on the place of residence at the time of their first participation in the SOEP. While it is possible that current place of residence and the associated gender norms also affect well-being, our argumentation refers to the place of socialization. Since regional movements are-despite substantial mobility from East to West Germany-still quite rare in our data, a detailed investigation that disentangles the effects of place of socialization and current residence is beyond the scope of our study.

\subsubsection{Confounders}

As we are interested in estimating the total effects of the respective employment transitions on the well-being of partners, we only adjust for time-varying variables that are assumed to 
affect individuals' probability to experience the transition as well as partners' life satisfaction. We do not control for variables that might be affected by the transitions to avoid overcontrol bias (Elwert and Winship 2014). This restriction excludes variables that are known to affect well-being, such as having children, but for which the direction of the relation to the independent variable of interest is not clear. We adjust for partners' age (squared) and year dummy variables to take account of confounding due to ageing effects and common time trends. We also control for the unemployment rate of the federal state where the couple lives (Statistik der Bundesagentur für Arbeit 2018). Poor regional labor market conditions likely decrease the probability of transitions from unemployment to fixed-term employment. In times of economic contraction, employers will be less willing to convert fixed-term into permanent contracts. High levels of unemployment have furthermore been shown to have an independent effect on individuals' well-being (Clark et al. 2010).

\subsubsection{Mediators}

We consider individuals' own well-being, their perceived job insecurity, and financial worries to partly mediate the effects of the transitions of interest on the well-being of partners. The well-being of individuals is measured by their life satisfaction on a scale from 0 to 10 (identical to the dependent variable). Perceived job insecurity and financial worries are measured by questions about how concerned individuals are about their job security and economic situation. For both variables we distinguish between those who are $(1=)$ "very" or "somewhat concerned" and those who are $(0=)$ "not concerned at all".

\subsection{Fixed-effects models}

To estimate the spillover effects of fixed-term employment on the well-being of partners, we apply fixed-effects panel regression models to our two samples. The first sample concerns transitions from unemployment to fixed-term, and the second from fixed-term to permanent employment. Our main specification for both samples is

$$
y_{i t}=\alpha T_{i t}+\beta T_{i t} F_{i}+\gamma X_{i t}+\delta X_{i t} F_{i}+\theta F_{i}+\mu_{i}+\epsilon_{i t}
$$

where $y_{i t}$ indicates the life satisfaction of the partner of individual $i$ in year $t . T_{i t}$ is a dummy variable for individual $i$ who experience the transition of interest. $F_{i}$ is a dummy variable for being female. $X_{i t}$ is a vector of confounding variables (including year fixed-effects). $\mu_{i}$ is a spell-specific fixed effect. $\epsilon_{i t}$ is the idiosyncratic error term. To give an example, for transitions from unemployment into fixed-term employment, $T_{i t}=0$ in the years before the transition, in which $i$ is unemployed, and $T_{i t}=1$ in the years after $i$ becomes and remains fixed-term employed. The spell-specific fixed effect $\mu_{i}$ is fixed within a specific treatment or control spell as well as couple. Thus, repeated spells within a couple or in different relationships are treated as separate observations. To consider that observations are nested in individuals and couples, standard errors are clustered at the highest level, that is, the couple level. As fixed-effects models only use variation within couples over time, the effects of any time-constant individual, partner, or couple characteristics are accounted for (Brüderl and Ludwig 2015). The coefficient $\alpha$ describes the spillover effect of transitions by men, while the combination of $\alpha+\beta$ gives the spillover effect of transitions by women. The interaction coefficient $\beta$ estimates the difference in the spillover effects. The test statistic of $\beta$ can be used to check whether gender differences in the effects of interest are statistically significant. 
While our main specification (1) allows to estimate the spillover effects separately for men and women (H1a to H2b), in some models we also include interaction terms with a dummy variable $E_{i}$, which indicates that individual $i$ 's partner was socialized in East instead of West Germany. Adding this dummy enables to examine how gender differences depend on the place of socialization $(\mathrm{H} 3 \mathrm{a}, \mathrm{b})$. These models allow all coefficients to vary by gender, partner's place of socialization, and their combination.

Moreover, we investigate the mediating role of individual $i$ 's own well-being (H4a, b), by estimating a model that adds their life satisfaction to our main specification (1). By comparing the total (main specification) and direct (main specification and mediator) spillover effects, we can learn how much of the former is mediated by changes in individuals' own well-being. To get a deeper understanding of how changes in the life satisfaction of the individual (the mediating variable) are themselves mediated (H5), we consider a model akin to specification (1), but where all variables refer to individual $i$. This model is estimated once excluding and once including the mediating variables job insecurity and financial worries. Thus, we can examine whether any effects on the well-being of the affected individual are mediated by a reduction in their perceived job insecurity and financial worries. These variables represent the main theoretical channels suggested in the literature.

\section{Results}

\subsection{The spillover effects and how gender differences vary by place of socialization}

Figure 1 provides the results for hypotheses H1a to H3b. It shows the spillover effects of transitions from unemployment to fixed-term (top panel a) and fixed-term to permanent employment (bottom panel b) on partners' well-being. Furthermore, it reveals how the spillover effects differ by gender as well as how these gender differences themselves

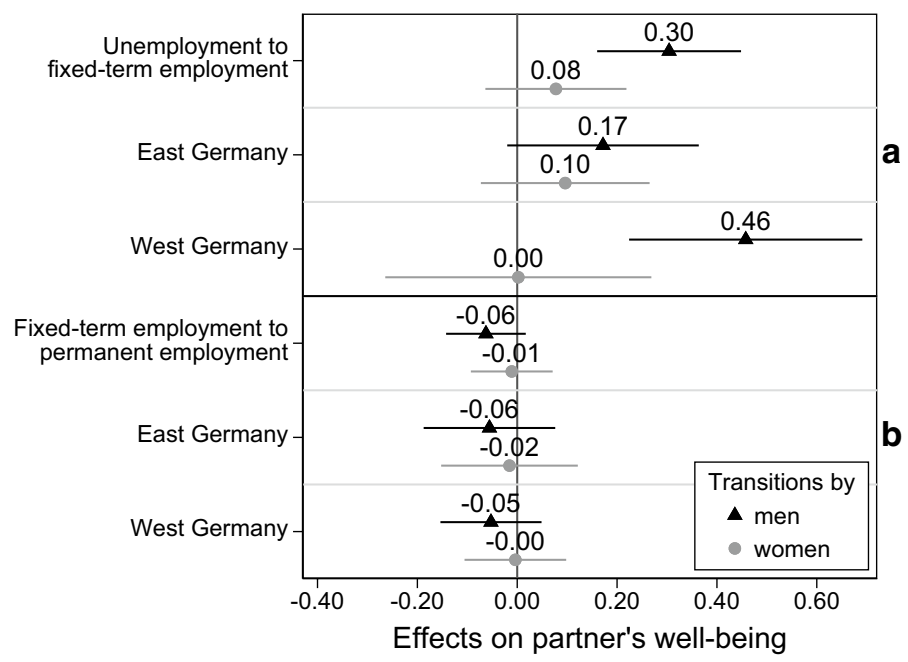

Fig. 1 Spillover effects of fixed-term employment on the well-being of partners and gender differences by place of socialization. Note: Socio-Economic Panel, version 34, 1995-2017. The top panel a shows the effects of transitions from unemployment to fixed-term employment and the bottom panel $\mathbf{b}$ of transitions from fixed-term to permanent employment 
depend on partners' socialization in East and West Germany. The coefficients and test statistics of the fixed-effects models used to calculate the shown conditional effects, including those of the control variables, can be found in Table S1 of Online Resource 1 (OR 1).

To empirically test H1a and H1b, we consider the first rows of the top (a) and bottom (b) panels of Fig. 1. These rows represent the spillover effects on partners' well-being depending on whether men or women experience the transition. In line with hypothesis H1a, we overall find that a transition from unemployment into fixed-term employment increases partners' well-being. The respective coefficients are positive for transitions of both men and women. At odds with hypothesis H1b, there is no such positive spillover effect for transitions from fixed-term to permanent employment. The coefficients are close to zero and even slightly negative.

Figure 1 shows the importance of gender when considering transitions from unemployment to fixed-term employment (panel a). If the male partner becomes re-employed in a fixed-term job, women experience a substantial increase in their well-being of 0.30 units. In contrast, if female partners take up fixed-term re-employment, male partners' well-being is less strongly positively affected. The gender difference in the effects is not only statistically significant, but also substantially important. The effect of male partners' transitions on female partners' well-being is almost four times larger than the effect of female partners' transition on male partners' well-being. Taken together, these results support H2a, suggesting that women benefit more from their male partners' transition from unemployment into fixed-term re-employment than vice versa. For transitions from fixed-term to permanent employment (panel b), we see very similar effects of either female or male partners' employment transitions on men's and women's well-being. These findings contradict hypothesis $\mathrm{H} 2 \mathrm{~b}$. The negative signs of these effects are inconsistent with the idea that transitions from fixed-term into permanent jobs improve partners' well-being.

Our results are at odds with the only previous study for the UK (Inanc 2018). This study finds that fixed-term as compared to permanent contracts have negative spillover effects on partners' well-being and that these differ by gender. Our findings on fixed-term re-employment are, however, consistent with studies that show that re-entering the labor market in these jobs has a positive effect on well-being (Gebel and Voßemer 2014; Gundert and Hohendanner 2014). Our findings are also in line with research on spillover effects of job losses and unemployment (Marcus 2013; Nikolova and Ayhan 2019).

However, spillover effects, and particularly gender differences in these, may depend on the place of socialization, as such contexts shape the prevailing gender norms. The second and third row of the top (a) and bottom (b) panels show the effects of each transition separately by gender and the partners' socialization in East or West Germany. We see a strong difference in the gendered effects for transitions from unemployment into fixed-term employment (a). For socialization in both East and West Germany, fixed-term re-employment by men seems to be more important for the female partner's well-being than vice versa. Nevertheless, for partners socialized in West Germany, the gender gap in the spillover effect is much larger, namely 0.46 units, whilst for socialization in East Germany it is only 0.07 units. The respective difference of 0.39 units in the gendered spillover effects by place of socialization is statistically significant. Overall, the results provide strong support for hypothesis $\mathrm{H} 3 \mathrm{a}$.

The picture is again less clear when it comes to gender differences in the spillover effects of transitions from fixed-term to permanent employment and their dependence on the place of socialization (b). When women make this transition, the well-being of male partners socialized in East Germany does not change much. Employment transitions by men slightly reduce the well-being of their female partners socialized in East Germany. 
There are no noteworthy differences in the effects for partners socialized in East and West Germany. All these effects are statistically insignificant, and their directions are contrary to our expectations. The interaction of the place of socialization is statistically insignificant and very close to zero. Overall, we find little evidence that the transitions from fixed-term to permanent employment have any positive effects on partners' well-being or that these effects vary by gender or its combination with place of socialization.

\subsection{Factors mediating the spillover effects}

To further test to what extent the spillover effects of fixed-term employment are mediated by changes in the directly affected individuals' well-being ( $\mathrm{H} 4 \mathrm{a}$ and $\mathrm{H} 4 \mathrm{~b}$ ), we estimate the main specification once without and once with controlling for this variable. The results are illustrated in Fig. 2, with the respective coefficients of the fixed-effects models being presented in Table S2 of OR 1.

The first coefficients in each row represent the total spillover effects estimated based on our main specification. These coefficients correspond to those reported in Fig. 1. Directly below each total spillover effect is the respective direct spillover effect, i.e., the effect of the employment transition after controlling for the mediating variable individuals' own wellbeing. The indirect effect equals the difference between the total and the direct effect.

When accounting for men's own subjective well-being in the spillover effect of unemployment to fixed-term employment transitions on female partners' well-being (panel a), the total effect of 0.30 units can be split up into a direct effect of 0.11 units and an indirect effect of 0.19 units $(0.30-0.11=0.19)$. The effect reduces by almost two-thirds, so that men's own well-being mediates a large share of the spillover effect on their female partners' well-being. The weaker total effect of women's transition from unemployment into fixed-term employment on the partners' well-being even becomes negative (direct effect

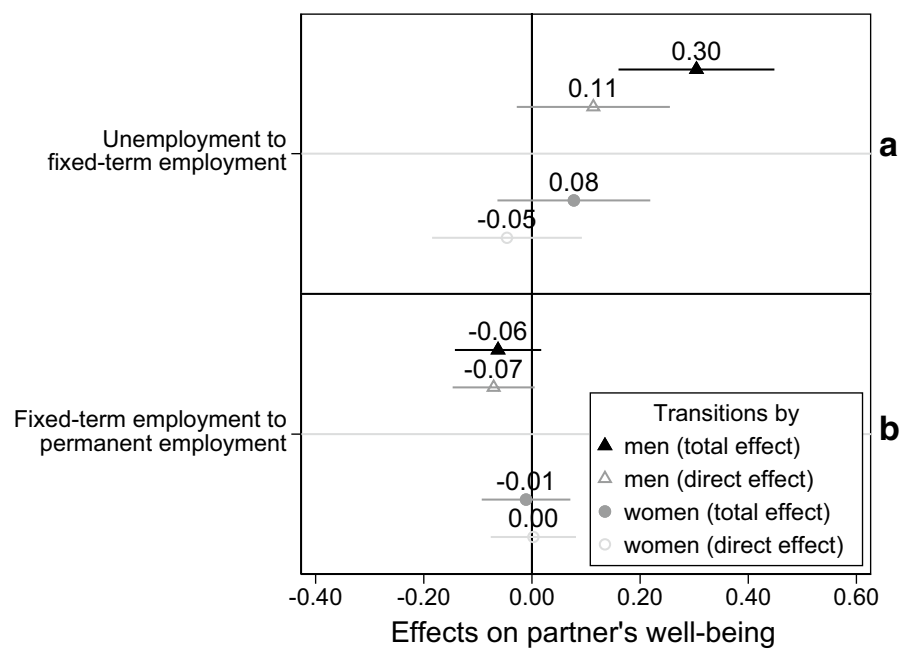

Fig. 2 Spillover effects of fixed-term employment on the well-being of partners by gender and the mediating role of the well-being of individuals. Note: Socio-Economic Panel, version 34, 1995-2017. The top panel a shows the effects of transitions from unemployment to fixed-term employment and the bottom panel b of transitions from fixed-term to permanent employment 
of -0.05 units) when accounting for their own subjective well-being. This finding suggests a mediation of the spillover effects for transitions from unemployment into fixed-term employment. Accordingly, the indirect effect equals 0.13 units $(0.08-(-0.05)=0.13)$.

The lower panel (b) refers to the transition from fixed-term into permanent employment. Controlling for the own subjective well-being does not substantially change the coefficients. The total and direct spillover effects are almost identical in case of both men's and women's transitions. Consequently, the indirect effects are very close to zero. Therefore, the small negative spillover effects of fixed-term to permanent employment transitions on the partners' well-being are not mediated by the own well-being.

Why is this case? One explanation for this finding may be that transitions from fixedterm to permanent employment not only have no spillover effects on the partners, but also do not alter the well-being of the directly affected individuals. Another explanation might be that improvements in the well-being of the individual itself are not transmitted to the partner. If there are no improvements in the well-being of the individual, it also becomes important to understand if this is due to the theoretically suggested mediating factors of reduced job insecurity and financial worries not coming into play.

Therefore, in a final step we estimate the effects of transitions from fixed-term to permanent employment on own well-being and examine whether these are mediated by changes in job insecurity and financial worries. Figure 3 shows the total effects for men and women as well as the direct effects after controlling for individual perceived job insecurity and financial worries. The coefficients of the corresponding fixed-effects models are reported in Table S3 of OR 1.

The coefficients in the upper row suggest that for men, transitions from fixed-term into permanent jobs increase their well-being by 0.03 units. As expected, this total effect is positive, but very small and statistically insignificant. This finding suggests that the absence of spillover effects can be explained by the fact that we only find negligible positive effects on the individuals themselves. To see whether the theoretical models referring to reduced job insecurity and financial worries are relevant, we estimate the direct effects by controlling

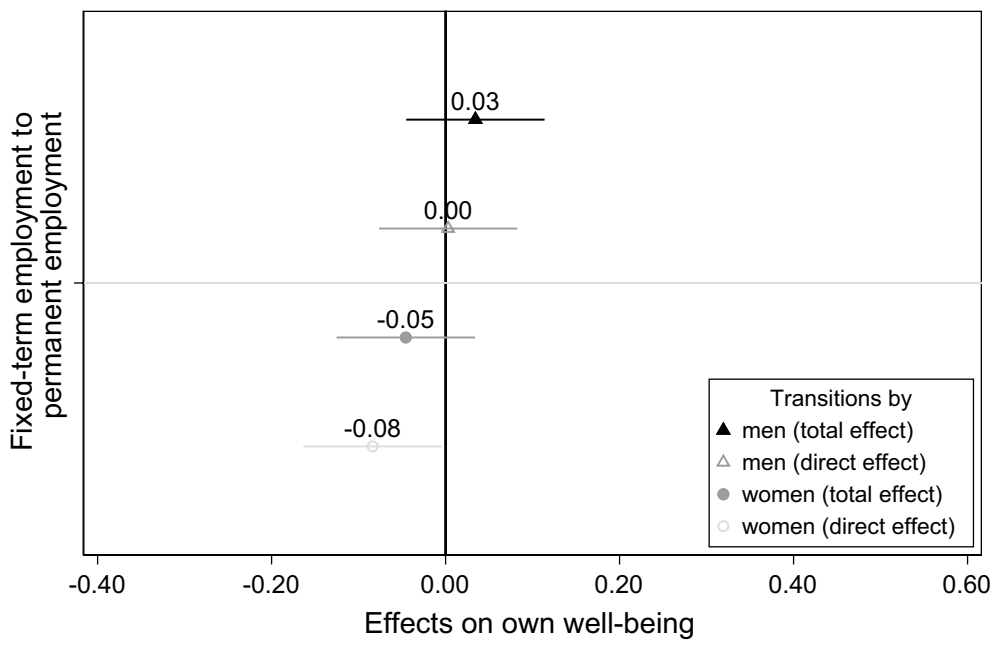

Fig. 3 Effects of fixed-term employment on the well-being of individuals by gender and the mediating role of individuals' perceived job insecurity and financial worries. Note: Socio-Economic Panel, version 34, 1995-2017. Only effects of transitions from fixed-term to permanent employment 
for these factors. These factors seem to mediate the total positive effect, since the direct effect equals zero. While this finding supports the theoretically assumed mechanisms, overall reduced job insecurity and financial worries together with other changes lead to only slight improvements in men's well-being.

In line with the previous findings on spillover effects, transitions from fixed-term to permanent employment slightly decrease women's own well-being (total effect of -0.05). Accounting for job insecurity and financial worries increases this negative impact further by 0.03 units (indirect effect) to -0.08 units (direct effect). The fact that the direct effect is more negative than the total effect is, however, in line with the theoretical explanations, which expect a positive indirect effect via reduced job insecurity and financial worries. In other words, by controlling for job insecurity and financial worries, we take out these positive indirect effects, such that the direct effect is more negative than the total effect.

In line with previous findings, we show that fixed-term employment as compared to permanent employment only slightly affects the well-being of individuals (Schumann and Kuchinke 2020; De Witte 2010; Gebel and Voßemer 2014). However, we do not find consistent effects across genders. If at all, transitions from fixed-term to permanent jobs seem to slightly decrease the well-being of women, while they only marginally increase the wellbeing of men.

\subsection{Robustness checks}

To further contextualize our findings regarding the spillover effects of transitions from unemployment to fixed-term and fixed-term to permanent employment, we examine the spillover effects of transitions from unemployment to permanent employment. We use our basic model specification including gendered spillover effects (OR 1, Table S4). We find that the spillover effects of transitions into permanent employment are only slightly larger ( 0.35 units for transitions by men, 0.07 units for the transitions by women) than the effects of transitions from unemployment to fixed-term employment ( 0.30 units for employment transitions by men, 0.07 units for respective transitions by women). Thus, for re-employment, the type of contract does not seem to matter much in terms of the spillover effects on well-being.

We also check the robustness of our results with respect to the age range of 18-65 years. We estimate our basic models only for individuals and partners who are between 20 and 45 years old (OR 1, Table S5). The effect sizes for the smaller age range do not differ significantly from our main analyses. Thus, our conclusions remain unchanged.

To examine possible heterogeneity within fixed-term employment, we use additional information on temporary agency work, that has been available in the SOEP since 2001. We distinguish between fixed-term temporary agency workers (TAW) and other fixed-term employees (NTAW). We estimate our basic model specification (OR 1, Table S6). For men, the positive spillover effect for transitions from unemployment to fixed-term employment is somewhat weaker for TAW ( 0.23 units) than for NTAW (0.31 units), while for women the effects are quite similar ( 0.14 units for TAW, 0.10 units for NTAW). For transitions from fixed-term to permanent employment, there is a positive effect for transitions from TAW by men ( 0.42 units) and women (0.39 units), and a negative effect for transitions from NTAW by men $(-0.14$ units) and women ( -0.06 units). While this indicates heterogeneity within fixed-term employment, these latter results are based on a very small number of observations in TAW. Consequently, the estimated effects are highly uncertain. In addition to this 
uncertainty, these results do not change our finding that, on average, there is no spillover effect for transitions from fixed-term to permanent employment.

\section{Discussion}

In this study, we extend the knowledge on how fixed-term employment affects well-being by addressing three research questions. First, are there spillover effects of fixed-term contracts on the well-being of partners? Second, do gendered spillover effects depend on socialization in East or West Germany? Third, are these spillover effects mediated by individual subjective well-being, job insecurity and financial worries? Using long-run panel data on couples from Germany, we analyze transitions from unemployment into fixed-term employment and from fixed-term into permanent employment. In this way, we look at the different perspectives on fixed-term employment by highlighting either their advantages or disadvantages.

We combine theoretical arguments from the vitamin model (Warr 2017) with the spillover-crossover model (Bakker and Demerouti 2013) to derive hypotheses about how fixedterm jobs may affect the well-being of partners. We estimate fixed-effects panel regression models, which reveal positive spillover effects of fixed-term re-employment as compared to remaining unemployed. These spillover effects are to a considerable extent mediated by individuals' own well-being. Our findings are consistent with arguments of the spillovercrossover model regarding the spillover of work into family life and with previous studies, which show that the negative effects of unemployment and job losses extend to partners (Marcus 2013; Nikolova and Ayhan 2019). The results reaffirm research, which suggests that fixed-term re-employment improves well-being over remaining unemployed (Gebel and Voßemer 2014).

We find that the positive spillover effects on partners' well-being are larger for transitions by men on women's well-being than for transitions by women on men's well-being. This difference is more pronounced for those who have been socialized in West as compared to East Germany. The findings support the idea that processes of doing gender are shaped by the place of socialization (Bauernschuster and Rainer 2012), and that the legacy of the GDR with respect to gender norms can still be seen (Ebner et al. 2020). Our findings are consistent with the vitamin model, which suggests that fixed-term employment offers more positive functions than unemployment. At the same time, the results are at odds with the idea that fixed-term employment has negative effects on the well-being of individuals similar to those of unemployment (Burchell 1994; Kim and von dem Knesebeck 2015). The results also contradict the findings of a recent study on spillover effects suggesting "that temporary work is at least as detrimental as unemployment for spouses' subjective well-being” (Inanc 2018, p. 1).

In contrast to the only previous study on spillover effects of fixed-term employment for the UK (Inanc 2018), we do not find that fixed-term jobs have any substantial negative effects on partners in comparison to permanent jobs for Germany. When analyzing transitions from fixed-term to permanent employment, we find little or no spillover effects of fixed-term employment and little differences by gender and place of socialization. We show that the absence of positive spillover effects of permanent employment can be explained by the fact that these transitions do not strongly affect the well-being of those individuals who experience the transitions. For women, we even find small negative effects of transitions into permanent employment. While we further reveal that the theoretical mechanisms of 
more vitamins via reduced job insecurity and financial worries are found to hold, these channels are not important enough to produce strong effects on individuals' own, let alone their partners' well-being.

Our findings are in line with previous research on Germany, which shows that reemployment matters more for well-being than the type of contract (Grün, Hauser and Rhein 2010; Gebel and Voßemer 2014). Considering the findings of Inanc for the UK (2018), our findings might be considered surprising. She expects the negative spillover effects and their gendered patterns to be stronger in labor markets that are more segmented, and in contexts where male-breadwinner norms are more strongly entrenched. This description arguably applies to West Germany. We show that these arguments matter when comparing the gendered spillover effects of fixed-term employment as compared to unemployment for partners socialized in East and West Germany. However, further cross-national comparative research is needed to reconcile the diverging results regarding the spillover effects of fixed-term as compared to permanent employment.

Despite the present study's strengths, some limitations remain. Even though the study focuses on specific transitions to consider asymmetric effects (Schumann and Kuchinke 2020), it does not extensively consider the heterogeneity within fixed-term employment (trajectories). While our robustness checks for fixed-term temporary agency workers indicate some differences, we face the same problem as previous studies, in that we cannot fully account for heterogeneity within fixed-term employment (Imhof and Andresen 2018).

Although we follow workers for all years in fixed-term employment before and after a specific transition, it might be that the negative effects of fixed-term employment only emerge if workers repeatedly experience such transitions and remain trapped in insecure jobs. This assumption can be analyzed by studying employment sequences, which include heterogenous forms of fixed-term employment, and outcome dynamics over longer periods. The current study design enables comparisons with previous studies, which also focused on single transitions, and provides first empirical evidence on spillover effects for Germany (Inanc 2018; Schumann and Kuchinke 2020).

Even though we complement previous studies by examining specific mediators such as job insecurity and financial worries on the individual level, we could not additionally account for mediators at the couple level (Baron and Rapp 2019). Delayed or even nonexistent transitions into first home ownership or the need to move several times due to frequent job changes might increase stress and consequently reduce the relationship quality (Blom et al. 2020). Since these events are strongly intertwined with employment careers, future research will profit from combing both domains. This strategy would also be in line with theoretical arguments and might give insights into cumulative disadvantages.

Overall, this article shows that the effects of employment transitions are not only limited to those individuals who experience it, but also affect their partners. This study furthermore provides evidence that the type of contract seems to be less relevant than being employed at all when it comes to spillover effects on partners' well-being in Germany. Regarding the scenarios of the integrative potential of fixed-term employment versus fears that persistent job insecurity leads to negative effects of similar magnitude or even worse than unemployment, the former scenario seems to prevail. The positive effect of fixed-term re-employment extends to partners, such that studies which only focus on the affected individuals might underestimate the positive overall effects such transitions entail.

Eventually, more in depth (cross-national) studies of the mediators that produce positive spillover effects of fixed-term re-employment will advance our understanding of the processes that link employment careers with partners' well-being. While we show that these spillover effects could be explained by the positive effects on the well-being 
of the directly affected individuals, we still need to understand in greater detail how the intertwined employment and family trajectories affect well-being of both partners in the longer run.

Acknowledgements The authors thank two anonymous reviewers as well as Michael Gebel, Anna Kiersztyn, Sophia Fauser, Florian Zimmermann, and Jonathan Latner for helpful discussions and comments. We also thank the discussants and participants of the RC06 Symposium at Rhodes and the ECSR-funded workshop "Labor Market Insecurity and Health of Family Members" at the University of Bamberg for their insightful comments and suggestions.

Funding Open Access funding enabled and organized by Projekt DEAL. This research has received funding from the European Research Council (ERC) under the Horizon 2020 research and innovation program (grant agreements No 758491 \& No 802631).

Data availability The data was made available by the German Institute for Economic Research (DIW Berlin). Neither the original collectors of the data, nor the archive, bear any responsibility for the analysis and presentations in this paper.

Code availability The computer code for the analysis is available at https://osf.io/xy6mn/.

\section{Compliance with ethical standards}

Conflicts of interest The authors declare no potential conflict of interest with respect to research, authorship, and publication of this article.

Open Access This article is licensed under a Creative Commons Attribution 4.0 International License, which permits use, sharing, adaptation, distribution and reproduction in any medium or format, as long as you give appropriate credit to the original author(s) and the source, provide a link to the Creative Commons licence, and indicate if changes were made. The images or other third party material in this article are included in the article's Creative Commons licence, unless indicated otherwise in a credit line to the material. If material is not included in the article's Creative Commons licence and your intended use is not permitted by statutory regulation or exceeds the permitted use, you will need to obtain permission directly from the copyright holder. To view a copy of this licence, visit http://creativecommons.org/licenses/by/4.0/.

\section{References}

Allison, P. D. (2019). Asymmetric fixed-effects models for panel data. Socius: Sociological Research for a Dynamic World. https://doi.org/10.1177/2378023119826441.

Auer, W., \& Danzer, N. (2016). Fixed-term employment and fertility: Evidence from German micro data. CESifo Economic Studies. https://doi.org/10.1093/cesifo/ifv014.

Bakker, A. B., \& Demerouti, E. (2013). The spillover-crossover model. In J. G. Grzywacz \& E. Demerouti (Eds.), New frontiers in work and family research (Current issues in work and organizational psychology). London: Psychology Press.

Bakker, A. B., Westman, M., \& van Hetty Emmerik, I. J. (2009). Advancements in crossover theory. Journal of Managerial Psychology. https://doi.org/10.1108/02683940910939304.

Barbieri, P. (2009). Flexible employment and inequality in Europe. European Sociological Review. https ://doi.org/10.1093/esr/jcp020.

Baron, D., \& Rapp, I. (2019). Does fixed-term employment delay important partnership events? Comparing transitions into cohabitation, marriage, parenthood and home ownership among young adults in Germany. Zeitschrift für Familienforschung, 31(1), 40-57. https://doi.org/10.3224/zff.v31i1.03.

Bauernschuster, S., \& Rainer, H. (2012). Political regimes and the family: How sex-role attitudes continue to differ in reunified Germany. Journal of Population Economics, 25(1), 5-27.

Blom, N., Verbakel, E., \& Kraaykamp, G. (2020). Couples' job insecurity and relationship satisfaction in the Netherlands. Journal of Marriage and Family, 82(3), 875-891. https://doi.org/10.1111/ jomf.12649. 
Blossfeld, H.-P., Buchholz, S., Mills, M., \& Kurz, K. (2005). Globalization, uncertainty, and youth in society. London: Routledge.

Booth, A. L., Francesconi, M., \& Frank, J. (2002). Temporary jobs: Stepping stones or dead ends? The Economic Journal, 112(480), F189-F213.

Bosmans, K., Hardonk, S., De Cuyper, N., \& Vanroelen, C. (2016). Explaining the relation between precarious employment and mental well-being: A qualitative study among temporary agency workers. Work, 53(2), 249-264.

Bossler, M., Gürtzgen, N., Kubis, A., \& Rebien, M. (2019). Befristungen bei Neueinstellungen: Aktualisiert Fassung vom 11. Juli 2019 (Aktuelle Daten und Indikatoren). Nuremberg: Institut für Arbeitsmarkt-und Berufsforschung.

Brüderl, J., \& Ludwig, V. (2015). Fixed-effects panel regression. In H. Best \& C. Wolf (Eds.), The SAGE handbook of regression analysis and causal inference (pp. 327-357). Thousand Oaks: SAGE.

Burchell, B. J. (1994). The effects of labour market position, job insecurity and unemployment on psychological health. In D. Gallie, C. Marsh, \& C. Vogler (Eds.), Social change and the experience of unemployment (pp. 188-212). Oxford: Oxford University Press.

Carter, M. (2014). Gender socialization and identity theory. Social Sciences, 3(2), 242-263. https://doi. org/10.3390/socsci3020242.

Chambel, M. J., Lopes, S., \& Batista, J. (2016). The effects of temporary agency work contract transitions on well-being. International Archives of Occupational and Environmental Health, 89(8), 1215-1228.

Clark, A., Knabe, A., \& Rätzel, S. (2010). Boon or bane? Others' unemployment, well-being and job insecurity. Labour Economics. https://doi.org/10.1016/j.labeco.2009.05.007.

Danner-Vlaardingerbroek, G., Kluwer, E. S., van Steenbergen, E., \& van der Lippe, T. (2013). Knock, knock, andybody home? Psychological availability as link between work and relationship. Personal Relationships, 20, 52-68.

Dawson, C., Veliziotis, M., \& Hopkins, B. (2017). Temporary employment, job satisfaction and subjective well-being. Economic and Industrial Democracy, 38(1), 69-98.

De Cuyper, N., De Jong, J., De Witte, H., Isaksson, K., Rigotti, T., \& Schalk, R. (2008). Literature review of theory and research on the psychological impact of temporary employment: Towards a conceptual model. International Journal of Management Reviews, 10(1), 25-51.

De Cuyper, N., Notelaers, G., \& De Witte, H. (2009). Transitioning between temporary and permanent employment: A two-wave study on the entrapment, the stepping stone and the selection hypothesis. Journal of Occupational and Organizational Psychology, 82(1), 67-88.

De Graaf-Zijl, M. (2012). Job satisfaction and contingent employment. De Economist, 160(2), 197-218. https://doi.org/10.1007/s10645-011-9180-7.

De Witte, H. (2010). Job Insecurity and psychological well-being: Review of the literature and exploration of some unresolved issues. European Journal of Work and Organizational Psychology, 8(2), 155-177.

De Witte, H., Pienaar, J., \& De Cuyper, N. (2016). Review of 30 years of longitudinal studies on the association between job insecurity and health and well-being: Is there causal evidence? Australian Psychologist. https://doi.org/10.1111/ap.12176.

Diener, E., Inglehart, R., \& Tay, L. (2013). Theory and validity of life satisfaction scales. Social Indicators Research. https://doi.org/10.1007/s11205-012-0076-y.

DiPrete, T. A., Goux, D., Maurin, E., \& Quesnel-Vallee, A. (2006). Work and pay in flexible and regulated labor markets: A generalized perspective on institutional evolution and inequality trends in Europe and the U.S. Research in Social Stratification and Mobility. https://doi.org/10.1016/j.rssm.2006.04.001.

Ebner, C., Kühhirt, M., \& Lersch, P. (2020). Cohort changes in the level and dispersion of gender ideology after German reunification: Results from a natural experiment. European Sociological Review. https://doi.org/10.1093/esr/jcaa015.

Elwert, F., \& Winship, C. (2014). Endogenous selection bias: The problem of conditioning on a collider variable. Annual Review of Sociology, 40, 31-53. https://doi.org/10.1146/annurev-soc-071913-043455.

Gash, V., Mertens, A., \& Gordo, L. R. (2007). Are fixed-term jobs bad for your health?: A comparison of west-Germany and Spain. European Societies, 9(3), 429-458.

Gebel, M., \& Voßemer, J. (2014). The impact of employment transitions on health in Germany. A difference-in-differences propensity score matching approach. Social Science \& Medicine, 128-136, https://doi.org/10.1016/j.socscimed.2014.02.039.

Goebel, J., Grabka, M. M., Liebig, S., Kroh, M., Richter, D., Schröder, C., et al. (2019). The German socio-economic panel (SOEP). Jahrbücher für Nationalökonomie und Statistik. https://doi. org/10.1515/jbnst-2018-0022.

Grün, C., Hauser, W., \& Rhein, T. (2010). Is any job better than no job? Life satisfaction and re-employment. Journal of Labor Research. https://doi.org/10.1007/s12122-010-9093-2. 
Gundert, S., \& Hohendanner, C. (2014). Do fixed-term and temporary agency workers feel socially excluded?: Labour market integration and social well-being in Germany. Acta Sociologica, 57(2), $135-152$.

Hobfoll, S. E. (1988). The ecology of stress. The series in health psychology and behavioral medicine. New York: Hemisphere.

Imhof, S., \& Andresen, M. (2018). Unhappy with well-being research in the temporary work context: Mapping review and research agenda. The International Journal of Human Resource Management, 29(1), 127-164.

Inanc, H. (2018). Unemployment, temporary work, and subjective well-being: The gendered effect of spousal labor market insecurity. American Sociological Review, 83(3), 536-566.

Jiang, L., \& Lavaysse, L. M. (2018). Cognitive and affective job insecurity: A meta-analysis and a primary study. Journal of Management. https://doi.org/10.1177/0149206318773853.

Kahneman, D., \& Tversky, A. (1979). Prospect theory: An analysis of decision under risk. Econometrica, 47(2), 263-291.

Kalleberg, A. L. (2018). Precarious lives: Job insecurity and well-being in rich democracies. Cambridge: Polity Press.

Karabchuk, T., \& Soboleva, N. (2020). Temporary employment, informal work and subjective wellbeing across Europe: Does labor legislation matter? Journal of Happiness Studies, 21(5), 18791901. https://doi.org/10.1007/s10902-019-00152-4.

Kim, T. J., \& von dem Knesebeck, O. (2015). Is an insecure job better for health than having no job at all? A systematic review of studies investigating the health-related risks of both job insecurity and unemployment. BMC Public Health, 15, 985. https://doi.org/10.1186/s12889-015-2313-1.

Korpi, T., \& Levin, H. (2001). Precarious footing: Temporary employment as a stepping stone out of unemployment in Sweden. Work, Employment \& Society, 15(1), 127-148.

Lazarus, R. S., \& Folkman, S. (1984). Stress, appraisal, and coping. New York: Springer.

Liebig, S., Schupp, J., Goebel, J., Richter, D., Schröder, C., Bartels, C., et al. (2019). Socio-economic panel (SOEP), data for years 1984-2017, version 34.

Luhmann, M., Hofmann, W., Eid, M., \& Lucas, R. E. (2012). Subjective well-being and adaptation to life events: A meta-analysis. Journal of Personality and Social Psychology, 102(3), 592-615.

Mantler, J., Matejicek, A., Matheson, K., \& Anisman, H. (2005). Coping with employment uncertainty: A comparison of employed and unemployed workers. Journal of Occupational Health Psychology. https://doi.org/10.1037/1076-8998.10.3.200.

Marcus, J. (2013). The effect of unemployment on the mental health of spouses-Evidence from plant closures in Germany. Journal of Health Economics. https://doi.org/10.1016/j.jhealeco.2013.02.004.

Mousteri, V., Daly, M., \& Delaney, L. (2018). The scarring effect of unemployment on psychological well-being across Europe. Social Science Research, 72, 146-169.

Nikolova, M., \& Ayhan, S. H. (2019). Your spouse is fired! How much do you care? Journal of Population Economics, 32(3), 799-844.

Nordenmark, M., \& Strandh, M. (1999). Towards a sociological understanding of mental well-being among the unemployed: The role of economic and psychosocial factors. Sociology. https://doi. org/10.1177/S003803859900036X.

Repetti, R., \& Wang, S.-W. (2017). Effects of job stress on family relationships. Current Opinion in Psychology. https://doi.org/10.1016/j.copsyc.2016.03.010.

Rodríguez-Muñoz, A., Sanz-Vergel, A. I., Demerouti, E., \& Bakker, A. B. (2014). Engaged at work and happy at home: A spillover-crossover model. Journal of Happiness Studies. https://doi. org/10.1007/s10902-013-9421-3.

Rook, K., Dooley, D., \& Catalano, R. (1991). Stress transmission: The effects of husbands' job stressors on the emotional health of their wives. Journal of Marriage and the Family. https://doi. org/10.2307/353141.

Sainsbury, D. (1996). Gender, equality, and welfare states. Cambridge: Cambridge University Press.

Scherer, S. (2009). The social consequences of insecure jobs. Social Indicators Research, 93(3), $527-547$.

Schumann, P., \& Kuchinke, L. (2020). Do(n't) worry, it's temporary: The effects of fixed-term employment on affective well-being. Journal of Happiness Studies, 21(7), 2557-2582. https://doi. org/10.1007/s10902-019-00194-8.

Silla, I., De Cuyper, N., Gracia, F. J., Peiró, J. M., \& de Witte, H. (2009). Job insecurity and well-being: Moderation by employability. Journal of Happiness Studies, 10(6), 739-751.

Statistik der Bundesagentur für Arbeit. (2018). Arbeitslosigkeit im Zeitverlauf. Nuremberg: Statistik der Bundesagentur für Arbeit. 
Täht, K., Xanthopoulou, D., Figgou, L., Kostouli, M., \& Unt, M. (2020). The role of unemployment and job insecurity for the well-being of young Europeans: Social inequality as a macro-level moderator. Journal of Happiness Studies, 21(7), 2355-2375. https://doi.org/10.1007/s10902-019-00184-w.

Veenhoven, R. (2009). How do we assess how happy we are? Tenets, implications and tenability of three theories. In A. Dutt \& B. Radcliff (Eds.), Happiness, economics and politics. Cheltenham: Edward Elgar Publishing.

Virtanen, M., Kivimäki, M., Joensuu, M., Virtanen, P., Elovainio, M., \& Vahtera, J. (2005). Temporary employment and health: A review. International Journal of Epidemiology, 34(3), 610-622.

Wanberg, C. R. (2012). The individual experience of unemployment. Annual Review of Psychology. https://doi.org/10.1146/annurev-psych-120710-100500.

Warr, P. (2017). Happiness and mental health: A framework of vitamins in the environment and mental process in the person. In C. L. Cooper \& J. C. Quick (Eds.), The handbook of stress and health (pp. 57-74). Chichester: Wiley.

West, C., \& Zimmermann, D. H. (1987). Doing gender. Gender and Society, 71(1), 125-151.

Westman, M. (2016). Old and new trends in crossover research. In T. D. Allen \& L. T. Eby (Eds.), Oxford library of psychology: The Oxford handbook of work and family (pp. 140-150). Oxford: Oxford University Press.

Publisher's Note Springer Nature remains neutral with regard to jurisdictional claims in published maps and institutional affiliations. 